\title{
On Prediction of Online Behaviors and Achievement Using Self-regulated Learning Awareness in Flipped Classrooms
}

\author{
Feng Hsu Wang
}

\begin{abstract}
The present research aims to explore the relationships between self-regulated learning (SRL) awareness, online behaviors and achievement by investigating whether SRL awareness measured at the beginning of the semester can predict online learning behaviors and achievement in the flipped classroom model. Psychometric data about SRL awareness and log data were collected and analyzed using multiple linear regression. Motivated Strategies for Learning Questionnaire (MSLQ) and a Moodle platform were used as data collection tools. Five flipped courses with a total of 93 undergraduates of a university in Taiwan were included in the present study. The results indicated that 1 ) task value, intrinsic motivation, control of learning beliefs and metacognition predict achievement, 2) SRL awareness predicts online behaviors to a limited extent, 3 ) combination of SRL awareness and online behaviors predicts achievement better than either one of the single-domain models. Theoretical contributions and implications for education and practice, and future research of the present study are discussed.
\end{abstract}

Index Terms-Flipped classroom, learning management system, online behavioral engagement, self-regulated learning.

\section{INTRODUCTION}

The flipped classroom model has attracted much research attention in recent years because of its potential for helping learners reach high levels of learning goals [1], [2]. The flipped classroom model is an approach to blended learning comprising an in-class face-to-face environment and an online learning environment supporting both in-class and out-of-class learning activities. In general, the flipped classroom model creates a learning environment requiring learners to exert their self-regulation skills to attain learning goals.

Numerous studies have examined the effectiveness of the flipped classroom approach compared to traditional lecture-based instructions, however, the results are inconsistent [3], [4]. One reason for these inconsistent findings may be that different characteristics of learners were not addressed [5]. Therefore, the present study is aimed to explore the relationships between self-regulated learning (SRL) awareness, online behaviors and achievement by investigating whether self-regulated learning awareness measured at the beginning of the semester can predict online

Manuscript received March 24, 2019; revised August 12, 2019. This work was sponsored by the Ministry of Science and Technology, Taiwan. under Grant no. MOST 107-2511-H-130-002.

F. H. Wang is with the Department of Computer Science and Information Engineering, Ming Chuan University, Taiwan (e-mail: fhwang@mail.mcu.edu.tw). learning behaviors and achievement in the flipped classroom model.

The present study focuses on several major components of SRL awareness, including motivation, self-efficacy and control of learning beliefs, metacognitive strategies and resource management [6]. SRL awareness was measured by Motivated Strategies for Learning Questionnaire (MSLQ) and learning behavior data were collected from five 18-week flipped courses supported by Moodle platform. A total of 93 valid unduplicated responses were collected. The relationships between SQL awareness, online learning behaviors and achievement were analyzed using correlation analysis and multiple linear regression.

\section{LITERATURE REVIEW}

\section{A. Flipped Classroom}

The flipped classroom model allows learners to control and participate in their learning processes autonomously through self-regulated learning [7]. Moreover, individual learners should be prepared for classroom learning activities before class. Since learners face pre-class activities alone, they need to develop self-regulating skills to regulate their motivation to complete pre-class activities [8], [9].

Flipped classrooms supported by a digital LMS platform create a learning environment that facilitates self-regulated learning [10], [11]. In particular, behavioral engagement in a flipped classroom could be enhanced if the learning environment encourages learners to develop skills to regulate by themselves and pursue self-formed goals [11], [12].

\section{B. Self-regulated Learning}

Self-regulated learning is defined as a learning process in which a learner systematically directs his thoughts, feelings, and behaviors towards his own objectives [13]. According to the self-regulating model proposed by Schraw, Crippen, and Hartley [14], the self-regulated learning process consists of three components: cognition, metacognition and motivation. The motivation component consists of self-efficacy and epistemological beliefs that affect the use and development of cognitive and metacognitive strategies in the SRL process. Cognition includes learning skills, such as cognitive strategies, problem-solving strategies, and critical thinking skills, which enable learners to encode, memorize and recall information [15]. The metacognition component includes skills that enable learners to understand and monitor cognitive processes.

One popular SRL survey tool is Motivated Strategies for 
Learning Questionnaire (MSLQ) [16]. The MSLQ survey featured Likert-type questions divided into two sections: motivation and learning strategies. The motivational section consists of value, expectancy beliefs, and affective components. The learning strategy section assesses three constructs: cognitive, metacognitive, and resource management [17]. The metacognitive construct measures learners' metacognitive self-regulation, whereas the resource management construct measures time and study environment, effort regulation, peer learning and help seeking.

SRL awareness has been shown significantly positively correlated with academic performance [11], [18]. However, most studies were based on cross-sectional data. On the other hand, engaging in self-regulatory behavior has been shown to be positively related to learning performance [19], [20]. However, there are relatively few studies on the effect of psychometric SRL awareness on behavioral engagement and long-term achievement [21], [22].

\section{METHODS}

\section{A. Study Setting}

The present study used a quantitative research approach that focused on levels of SRL awareness, online behavior, and achievement of undergraduates in flipped courses. The quantitative data includes MSLQ survey data for measuring SRL awareness and log data for online behavior. Five courses offered by the researcher are the focus of the study. The flipped courses were designed based on Merrill's model [23], consisting of activation, demonstration, application and integration stages. Before each class began, learners studied online material to get ready for classroom problem-solving activities, in which learners were grouped to solve problems, access and discuss related resources. Learners were asked to upload their work to Moodle at the end of the class. After class learners can continue to complete unfinished assignments within a week or consolidate what they have learned by solving other problems or conduct self-assessment in Moodle. Finally, to promote learning through reflection, a three-minute report per week and a self-reflection of the mid-term testing results were conducted through Moodle's questionnaire module.

Each course lasted 18 weeks. The time allotted for one class per week was $150 \mathrm{~min}$. MSLQ survey data were collected in the fourth week to assess learners' initial SRL awareness. The reason that the survey was conducted in the fourth week is to allow learners enough time (at least 3 weeks) to adapt to SRL strategies successfully, as suggested by Yilmaz and Baydas [7]. A total of 93 valid unduplicated responses were used in the survey analysis. All courses were conducted by the same instructor in computer classrooms facilitated by the Moodle platform, without teaching assistants or any e-moderators.

\section{B. Data Collection and Preparation}

The original MSLQ survey had 81 statements, whereas in the current study 53 statements suitable for the research purpose were selected. These statements are rated on a five-point Likert scale, ranging from "not at all true of me" (1) to "very true of me" (5). The reverse questions in the questionnaire were also properly handled. The individual learner's SRL awareness of a subscale is calculated based on the average of his responses to the subscale's questionnaire items. The higher the score, the higher the learner's SRL awareness regarding the specific subscale.

The second method of data collection was $\log$ data that recorded learners' online behaviors in Moodle. An activity that spanned less than 5 seconds or longer than one hour was ignored [24]. The learner's achievement is his final grade. According to the four-component model proposed by Wang [25], the behavioral constructs derived from LMS data include online study, social interaction, problem solving and self-reflection and self-assessment. To measure online behavioral engagement, the present study adopts the frequency-based and duration-based approaches [25]. Moreover, the behavioral constructs, except for the Self-reflection and Self-assessment, were divided into in-class behavioral constructs and out-of-class behavioral constructs according to the time when the activities occurred. All behavioral measurements, and the final grade for each course are converted to $\mathrm{z}$-scores before being merged into the data set.

\section{Procedure}

First, the reliability of MSLQ subscales and online behavioral constructs is validated with Cronbach's alpha (values above .7 indicate good reliability). Thereafter, we analyzed: correlations between the MSLQ subscales and online behavior; correlations between the MSLQ subscales and achievement; and correlations between online behavior and achievement. Second, we conducted multiple linear regression to assess: the ability of the MSLQ subscales to predict online behavior, the ability of the MSLQ subscales to predict achievement, the ability of online behavior to predict achievement, and the ability of combining MSLQ subscales and online behavior to predict achievement.

\section{RESULtS}

\section{A. Correlation Analysis}

Since the data does not conform to the normal distribution, Spearman's correlation analysis was first conducted to analyze the zero-order correlation between MSLQ subscales. The results show that all Cronbach's alpha values are above 0.7 , except for the Persistency subscale which is 0.59 . Table I shows the correlation between the MSLQ subscales and achievement. Correlation coefficients above 0.6 indicate a strong relationship, moderate if between 0.4 and 0.6 , weak if between 0.2 and 0.4 , otherwise, it is none or very weak. The correlations of Intrinsic Motivation, Task Value, Time Management and Metacognition with achievement were significant but weak, whereas the rest of the MSLQ subscales were not found significantly related to achievement. 
TABLE I: SPEARMAN CORRELATION COEFFICIENTS BETWEEN THE MSLQ SUBSCALES AND ACHIEVEMENT $(\mathrm{AC})(N=93)$

\begin{tabular}{cccccccccc}
\hline & IM & EM & TV & CL & SE & TM & MC & PS & PL \\
\hline AC & $0.31^{*}$ & 0.1 & $0.28^{* *}$ & 0.1 & 0.13 & $0.21^{*}$ & $0.24^{*}$ & 0.14 & 0.12 \\
\hline$(*<0.05, * *<0.01)$ & & & & & & &
\end{tabular}

Table II shows the Spearman correlation coefficients between MSLQ subscales and online behaviors. The correlations were either weak or none. Note that awareness of Extrinsic Motivation and Peer Learning did not relate to any online behavior significantly.

TABLE II: SPEARMAN CORRELATION COEFFICIENTS BETWEEN MSLQ SUBSCALES AND ONLINE BEHAVIORS $(N=93)$

\begin{tabular}{clllllll}
\hline \multicolumn{7}{c}{ SUBSCALES AND ONLINE BEHAVIORS $(N=93)$} \\
Subscale & SD_I & IA_I & AS_I & SD_O & IA_O & AS_O & SA \\
\hline IM & $0.21^{*}$ & $0.33^{* * *}$ & $0.22^{*}$ & $0.32^{* *}$ & $0.30^{* * *}$ & $0.31^{* *}$ & 0.25 \\
EM & 0.03 & 0.12 & -0.06 & 0.15 & 0.18 & 0.11 & 0.02 \\
TV & 0.14 & $0.35^{* * *}$ & $0.23^{*}$ & 0.17 & 0.18 & $0.21^{*}$ & 0.15 \\
CL & 0.11 & $0.25^{*}$ & 0.12 & 0.14 & 0.16 & 0.14 & 0.17 \\
SE & 0.14 & $0.28^{* *}$ & $0.25^{*}$ & 0.20 & $0.25^{*}$ & 0.20 & 0.12 \\
TM & $0.32^{* *}$ & $0.35^{* * *}$ & $0.27^{* *}$ & $0.27 *^{* *}$ & $0.34^{* * *}$ & $0.25^{*}$ & $0.29^{* * *}$ \\
MC & $0.22^{*}$ & $0.36^{* * *}$ & $0.29^{* *}$ & $0.22^{*}$ & $0.29^{* *}$ & $0.21^{*}$ & $0.22^{*}$ \\
PS & 0.17 & $0.29^{* *}$ & 0.16 & $0.26^{*}$ & 0.20 & $0.21^{*}$ & 0.18 \\
PL & 0.15 & 0.18 & 0.16 & 0.14 & 0.14 & 0.16 & 0.11 \\
\hline (*<0.05, **<0.01, ***<0.001) & & & &
\end{tabular}

The Spearman correlation coefficients of the relationships between online behaviors and achievement are shown in Table III, which shows that engagement in out-of-class online study, social interaction and problem solving had strong or moderate relationships with achievement, whereas the rest of online behaviors had weak relationships with achievement.

TABLE III: SPEARMAN CORRELATION COEFFICIENTS BETWEEN BEHAVIORS AND ACHIEVEMENT $(N=93)$

\begin{tabular}{cccccccc}
\hline & SA & SD_I & IA_I & AS_I & SD_O & IA_O & AS_O \\
\hline AC & $0.35^{* * *}$ & $0.30^{* *}$ & $0.38^{* * *}$ & $0.31^{* *}$ & $0.62^{* * *}$ & $0.53^{* * *}$ & $0.56^{* * *}$ \\
\hline$(*<0.05, * *<0.01, * * *<0.001)$ & & & & &
\end{tabular}

\section{B. Multiple Linear Regression Analysis}

First, multicollinearity among the MSLQ subscales was measured by variance inflation factors (VIF). If the VIF value exceeds 10.0, there is a serious problem with multicollinearity [26]. Table IV shows the VIF values for each MSLQ subscale, and no serious multicollinearity is detected.

TABLE IV: VIF FOR INITIAL MSLQ SUBSCALES TO PREDICT ACHIEVEMENT $\begin{array}{cccccccccc}\begin{array}{c}\text { MSLQ } \\ \text { Subcales }\end{array} & \text { IM } & \text { EM } & \text { TV } & \text { CL } & \text { SE } & \text { TM } & \text { MC } & \text { PS } & \text { PL } \\ \text { VIF } & 2.96 & 1.64 & 3.76 & 3.26 & 3.42 & 1.67 & 3.90 & 1.70 & 2.39\end{array}$

Multiple linear regressions were carried out to investigate whether the SRL-awareness factors could predict online behavior and achievement. First, a significant regression equation using SRL-awareness factors to predict achievement was found $(F(9,83)=3.296, p<.01)$, explaining $26.3 \%$ of the variance in achievement. Four SRL-awareness factors were found significant, including Intrinsic Motivation $(\beta=.361, p<.05)$, Task Value $(\beta=.428, p<.05)$, Control of Learning Beliefs $(\beta=-.562, p<.01)$, and Metacognition $(\beta=.410, p<.05)$.
To investigate the relationships between SRL awareness and online behavior, multiple regressions were applied separately for each type of behavioral engagement using SRL-awareness factors as predictors. As shown in Table V, a significant regression equation using SRL-awareness factors to predict out-of-class online study was found $(F(9$, $83)=2.303, p<.05, R 2=0.200)$, and Intrinsic Motivation $(\beta$ $=.637, p<.05)$ positively predicts out-of-class online study. Moreover, a significant regression equation using SRL-awareness factors to predict out-of-class social interaction was found $(F(9,83)=3.431, p<.01, R 2=0.271)$, and Time Management $(\beta=.786, p<.05)$ positively predicts out-of-class social interaction, whereas Peer Learning ( $\beta=$ -.525, $p<.05)$ negatively predicts out-of-class social interaction. It seems Peer Learning was a suppressor variable in the behavior prediction model, as its zero-order correlations with online behaviors were weak (see Table II). No significant SRL-awareness predictors were found for the rest of online behaviors.

Next, multiple linear regressions were carried out to investigate whether online behaviors predict achievement. Table VI shows that no serious multicollinearity was detected for the behavioral constructs. A significant regression equation for achievement prediction using online behaviors was found $(F(7.85)=7.824, p<.000)$, explaining $39.2 \%$ of the variance. In-class Social Interaction $(\beta=.248, p<.05)$ and Out-of-class Online Study $(\beta=.591, p<.01)$ significantly contributed to the model.

TABLE V: MULTIPLE LINEAR REGRESSION MODELS USING SRL-AWARENESS FACTORS TO PREDICT EACH TYPE OF BEHAVIORAL ENGAGEMENT

\begin{tabular}{|c|c|c|c|c|c|c|c|}
\hline Behav. & MSLQ & $\beta$ & $\begin{array}{l}\text { Std. } \\
\text { Err. }\end{array}$ & $\operatorname{Pr}(>|t|)$ & $\begin{array}{l}\text { Multiple } \\
\text { R-squared }\end{array}$ & $\begin{array}{c}\text { F-value } \\
\text { (df1, } \\
\text { df2) }\end{array}$ & p-value \\
\hline SA & $\mathrm{TM}$ & 0.429 & 0.222 & $0.057^{+}$ & 0.116 & $\begin{array}{c}1.208 \\
(9,83)\end{array}$ & 0.302 \\
\hline SD_I & $\mathrm{TM}$ & 0.359 & 0.197 & 0.073 & 0.133 & $\begin{array}{c}1.418 \\
(9,83)\end{array}$ & 0.194 \\
\hline IA_I & - & - & - & - & 0.123 & $\begin{array}{c}1.293 \\
(9,83)\end{array}$ & 0.253 \\
\hline AS_I & EM & -0.276 & 0.139 & $0.050^{*}$ & 0.163 & $\begin{array}{c}1.799 \\
(9,83)\end{array}$ & 0.081 \\
\hline SD_O & IM & 0.637 & 0.246 & $0.011^{*}$ & 0.200 & $\begin{array}{c}2.303 \\
(9,83)\end{array}$ & $0.023^{*}$ \\
\hline \multirow{3}{*}{ IA_O } & IM & 0.518 & 0.266 & $0.055^{+}$ & \multirow{3}{*}{0.271} & \multirow{3}{*}{$\begin{array}{c}3.431 \\
(9,83)\end{array}$} & \multirow{3}{*}{$0.0012^{* *}$} \\
\hline & $\mathrm{TM}$ & 0.786 & 0.311 & $0.013^{*}$ & & & \\
\hline & PL & -0.525 & 0.230 & $0.025^{*}$ & & & \\
\hline \multirow{2}{*}{ AS_O } & $\mathrm{IM}$ & 0.462 & 0.240 & $0.058^{+}$ & \multirow{2}{*}{0.159} & \multirow{2}{*}{$\begin{array}{c}1.743 \\
(9,83)\end{array}$} & \multirow{2}{*}{0.092} \\
\hline & TM & 0.470 & 0.280 & 0.097 & & & \\
\hline
\end{tabular}

$(*<0.05, * *<0.01, * * *<0.001)$

TABLE VI: VIF FOR ONLINE BEHAVIORAL ENGAGEMENT TO PREDICT ACHIEVEMENT

\begin{tabular}{cccccccc}
\hline Behav. & SD_I & IA_I & AS_I & SD_O & IA_O & AS_O & SA \\
\hline VIF & 2.047 & 2.062 & 2.344 & 4.515 & 2.563 & 4.034 & 2.234 \\
\hline
\end{tabular}

Finally, multiple linear regression analysis was used to measure the ability of using SRL awareness factors and 
online behaviors together to predict achievement. Again, no serious multicollinearity was detected for the predictors. A significant regression equation was found for the achievement prediction model $(F(16,76)=4.958, p<.000)$, with an R2 of .511. The predictive power of the models is stronger than their counterparts with either SRL awareness or behavioral predictors alone. Three SRL awareness predictors, Task Value $(\beta=.359, p<.05)$, Control of Learning Beliefs $(\beta=-.344, p<.05)$, and Metacognition $(\beta$ $=.336, p<.05)$, and one behavioral predictor, Out-of-class Online Study $(\beta=.464, p<.05)$, were found to be significant. Note that the estimated coefficients of Control of Learning Beliefs were negative.

\section{DisCUSSION}

The relationship between SRL awareness and achievement and between SRL awareness and online behavior were weak. This is in line with Vogt's argument that research based on the self-report method on the connection between learners' genuine learning behavior and learners' perceptual engagement was found either minimal or non-significant [27]. On the other hand, the relationship between online behavior and achievement was stronger. Previous studies have found a correlation between online learning behavior and achievement [28], [29]. It reveals that LMS data could itself serve as a source of a seamless, real-time and non-invasive measure of behavioral engagement in the flipped classroom model supported with an online component [25], [30]

Regarding the regression models, the R-squares of the single-domain models with SRL awareness predictors and behavioral predictors were respectively 0.263 and 0.392 . These models were satisfactory regarding the use of single-domain predictors to predict long-term learning performance. In contrast, the R-square of the regression model using both SRL awareness and behavioral predictors was 0.511 , resulting in a better model that accounted for more variance than either one of the single-domain models. Moreover, only out-of-class online study and out-of-class social interaction were found significantly predictable by SRL-awareness factors. The results reveal that the SRL awareness measured at the beginning of the semester may not explain the long-term online behaviors and achievement appropriately because learners' motivation states may change dynamically as the learning context changes during the semester. This finding is consistent with the study [31], which suggested that the observable indicators can better explain learning performance than preliminary subjective assessments. Moreover, the present study suggests that using both the psychometric SRL awareness factors and the genuine online behavioral factors could help establish a better prediction model of achievement.

In addition, the present study shows that task value, control of learning beliefs, metacognition and out-of-class online study predict achievement significantly. Moreover, the results suggest that task value be the strongest psychometric predictor of achievement, whereas engagement in out-of-class online study be the strongest behavioral predictor of achievement in the flipped classrooms. The research results are in line with previous ones which show that task value has an important effect on student learning outcomes [15], [32][31]-[34]. Moreover, several researches showed that metacognitive strategies are more closely related to achievement [35]-[38].

Note that awareness of control of learning beliefs had large negative coefficients in all the regression models, indicating that it may be a suppressor variable, since the zero-ordered correlations of control of learning beliefs with achievement was small (see Table I). Therefore, it suggests that there be negative interactions between the control of learning beliefs and other factors in the models, explanations of which are yet to be explored.

\section{CONCLUSION}

The present study demonstrates that LMS data can be used as a source of behavioral engagement metrics, supplementing student self-reported motivational data to predict achievement [27], [28]. Moreover, the present study shows that a mixed method that combines self-reported data and online behavioral engagement can provide a superior method than either one, which could have the potential to offer insights about the dynamics of motivation and behavioral engagement in flipped classrooms that, heretofore, have yet to be fully explored.

\section{A. Implications for Education and Practice}

First, the SRL-awareness factors, task value and metacognition, were significant positive predictors of achievement, implying that active problem-solving activities may attract learners with higher sense of task value and metacognition in the flipped classrooms. Therefore, teachers need to pay attention to the value that learners attach to their courses, for example, by designing authentic problem-solving activities that meet learners' task value and raise learners' metacognitive awareness by helping them better manage their cognitive learning during the problem-solving process. Moreover, teachers need to help learners develop metacognitive skills, for example, by presenting information in a way that exerts higher order thinking. Second, engagement in out-of-class online study significantly predicts achievement. Moreover, raising awareness of intrinsic motivation could help learners engage in out-of-class online study. Therefore, teachers should raise learners' intrinsic motivation, for example, by providing instructive feedback, encouraging collaboration and helping learners setting up greater goals. Teachers should also provide active-problem solving activities that could help engage learners in out-of-class online study to achieve high levels of achievement.

\section{B. Limitations and Suggestions for Future Research}

First, the data size is small ( $n=93)$, which may limit the generality of the findings. Second, the average of the learners' SRL awareness scores was used in the regression 
model. This could be considered a limitation of the study. Third, the present study focused only on courses conducted by the same instructor. Therefore, more extensive evaluation is needed to see the replicability of the findings in courses conducted by different instructors. Fourth, because only a special student population in the computer discipline was involved in the present study, discretion must be exerted to apply the results to other populations and disciplines. Finally, the present study was an exploratory study, and further controlled experiments on the causality that may be implied by the relationships are encouraged.

The present study raises several questions for research. First, it is necessary to study why the awareness of control of learning beliefs negatively predicts achievement. Second, although the present study identifies several important SRL-awareness and behavioral factors related to achievement, a further analysis of the inter-relationships between the SRL-awareness and behavioral factors may provide deeper insights that can better explain how these factors affect learners' achievement. Third, controlled experiments are needed to confirm the influence of these psychometric and behavioral factors on achievement.

\section{CONFLICT OF INTEREST}

The authors declare no conflict of interest.

\section{AUTHOR CONTRIBUTIONS}

The single author F. H. Wang conducted the research, data analysis and paper writing.

\section{REFERENCES}

[1] M. Akgün and B. Atıc1, "The effect of flipped classroom on learners' academic achievements and views," Kastamonu Education Journal, vol. 25, no. 1, pp. 329-344, 2017.

[2] I. T. Awidi and M. Paynter, "The effect of a flipped classroom approach on student learning experience," Computers \& Education, vol. 128, pp. 269-283, 2019.

[3] J. A. Arnott and S. L. Planey, "Flipped classroom approaches lead to no improvement in learning outcomes or student perceptions," FASEB Journal, vol. 31, no. 1, pp. 751-14, 2017.

[4] E. Sengel, "To FLIP or not to FLIP: Comparative case study in higher education in Turkey," Computers in Human Behavior, vol. 64, pp. 547-555, 2016

[5] Z. Sun, "The role of self-regulation on learners' learning in an undergraduate flipped math class," Doctoral dissertation, The Ohio State University, 2015.

[6] B. J. Zimmerman, "Self-regulated learning and academic achievement: An overview," Educational Psychologist, vol. 25, no. 1, 3-17, 1990.

[7] R. M. Yilmaz and O. Baydas, "An examination of undergraduates' metacognitive strategies in pre-class asynchronous activity in a flipped classroom," Education Tech Research Dev., 65:1547-1567, 2017.

[8] S. R. Sletten, "Investigating flipped learning: Student self-regulated learning, perceptions, and achievement in an introductory biology course," Journal of Science Education and Technology, vol. 3, no. 26 , pp. 347-358, 2017

[9] C. A. Wolters, P. R. Pintrich, and S. A. Karabenick, "Assessing academic self-regulated learning," What do Children Need to Flourish: Conceptualizing and Measuring Indicators of Positive Development, Springer Science Business Media, Berlin, New York, NY, 2005, pp 251-270.

[10] J. C.-Y. Sun and R. Rueda, "Situational interest, computer self-efficacy and self-regulation: Their effect on student engagement in distance education," British Journal of Educational Technology, vol. 43, no. 2, pp. 191-204, 2012.

[11] Z. Sun, K. Xie, and L. H. Anderman, "The role of self-regulated learning in learners' success in flipped undergraduate math courses," The Internet and Higher Education, vol. 36, pp. 41-53, 2018.
[12] A. T. Steen-Utheim and N. Foldnes, "A qualitative investigation of student engagement in a flipped classroom," Journal of Teaching in Higher Education, vol. 23, no. 3, pp. 307-324, 2017.

[13] B. J. Zimmerman and D. H. Schunk, Self-regulated Learning and Academic Achievement Theoretical Perspectives, 2nd ed., Mahwah, NJ: Erlbaum, 2001.

[14] G. Schraw, K. J. Crippen, and K. Hartley, "Promoting self-regulation in science education: Metacognition as part of a broader perspective on learning," Research in Science Education, vol. 36, no. 1-2, pp. 111-139, 2006.

[15] P. R. Pintrich, "The role of motivation in promoting and sustaining self-regulated learning," International Journal of Educational Research, vol. 31, no. 6, pp. 459-470, 1999.

[16] P. R. Pintrich, A Manual for the Use of the Motivated Strategies for Learning Questionnaire (MSLQ), Ann Arbor, MI: National Center for Research to Improve Postsecondary Teaching and Learning, 1991.

[17] T. García and P. R. Pintrich, "Assessing students' motivation and learning strategies: The Motivated Strategies for Learning Questionnaire (MSLQ)," presented at the Annual Meeting of the American Educational Research Association, 1995, San Francisco, CA: ERIC Document Reproduction Service No. ED 383770.

[18] L. Nota, S. Soresi, and B. J. Zimmerman, "Self-regulation and academic achievement and resilience: A longitudinal study," International Journal of Educational Research, vol. 41, pp. 198-215, 2004.

[19] R. Garcia, K. Falkner, and R. Vivian, "Systematic literature review: Self-regulated learning strategies using e-learning tools for computer science," Computers \& Education, vol. 123, pp. 150-163, 2018.

[20] M. Oi, C. J. Yin, F. Okubo, A. Shimada, K. Kojima, M. Yamada, and H Ogata, "Analysis of links among e-books in undergraduates' e-book logs," Workshop Proceedings of the 23th International Conference on Computers in Education, pp. 665-669, 2015.

[21] B. Giesbers, B. Rienties, D. Tempelaar, and W. Gijselaers, "Investigating the relations between motivation, tool use, participation and performance in an e-learning course using web-videoconferencing," Computers in Human Behavior, vol. 29, pp. 285-292, 2013.

[22] M. Yamada, A. Shimada, F. Okubo, M. Oi, K. Kojima, and H. Ogata, "Learning analytics of the relationships among self-regulated learning, learning behaviors, and learning performance," Research and Practice in Technology Enhanced Learning, pp. 12-13, 2017.

[23] M. D. Merrill, First Principles of Instruction: Identifying and Designing Effective, Efficient, and Engaging Instruction, San Francisco, CA: Pfeiffer, 2013.

[24] Q. Nguyen, B. Rienties, and M. Huptych, "Linking learners' timing of engagement to learning design and academic performance," in Proc. the 8th International Conference on Learning Analytics \& Knowledge, Sydney, Australia, 2018.

[25] F. H. Wang, "An exploration of online behavioral engagement and achievement in flipped classroom supported by learning management system," Computers \& Education, vol. 114, pp. 79-91, 2017.

[26] J. F. Hair, G. T. M. Hult, C. M. Ringle, and M. Sarstedt, A Primer on Partial Least Squares Structural Equation Modeling (PLS-SEM), USA Sage Publication, 2014.

[27] K. L. Vogt, "Measuring student engagement using learning management systems," $\mathrm{Ph}$. D. thesis, Ontario Institute for Studies in Education, Leadership, Higher \& Adult Education, University of Toronto, 2016.

[28] C. R. Henrie, R. Bodily, K. C. Manwaring, and C. R. Graham, "Exploring intensive longitudinal measures of student engagement in blended learning," International Review of Research in Open and Distributed Learning, vol. 16, no. 3, pp. 131-155, 2015.

[29] A. Pardo, F. Han, and R. A. Ellis, "Combining university student self-regulated learning indicators and engagement with online learning events to predict academic performance," IEEE Transactions on Learning Technologies, vol. 10, no. 1, pp. 82-92, 2017.

[30] C. R. Henrie, L. R. Halverson, and C. R. Graham, "Measuring student engagement in technology-mediated learning: A review," Computers \& Education, vol. 90, pp. 36-53, 2015.

[31] A. Cicchinelli, E. Veas, A. Pardo, V. Pammer-Schindler, A. Fessl, C. Barreiros, and S. Lindstadt, "Finding traces of self-regulated learning in activity streams," in Proc. the 8th International Conference on Learning Analytics and Knowledge, vol. 99. pp. 191-200, Sydney, NSW, Australia, 2018.

[32] I. S. Al-Harthy and S. S. Aldhafri, "The relationship among task-value, self-efficacy and academic achievement in Omani sudents at Sultan Qaboos University," International Review of Social Sciences and Humanities, vol. 7, no. 2, pp. 15-22, 2014.

[33] K. D. Burton, J. E. Lydon, D. U. D'Alessandro, and R. Koestner, "The differential effects of intrinsic and identified motivation on well-being and performance: Prospective, experimental, and implicit approaches to self-determination theory," Journal of Personality and Social Psychology, vol. 91, no. 4, pp. 750-762, 2006. 
[34] A. D. Liem, S. Lau, and Y. Nie, "The role of self-efficacy, task value, and achievement goals in predicting learning strategies, task disengagement, peer relationship, and achievement outcome," Contemporary Educational Psychology, vol. 33, no. 4, pp. 486-512, 2008.

[35] R. Abdellah, "Metacognitive awareness and its relation to academic achievement and teaching performance of pre-service female teachers in Ajman University in UAE," Procedia - Social and Behavioral Sciences, vol. 174 , pp. $560-567,2015$.

[36] R. Azevedo, "Using hypermedia as a metacognitive tool for enhancing student learning? The role of self-regulated learning," Educational Psychologist, vol. 40, no. 4, pp. 199-209, 2005.

[37] A. L. Dent and A. C. Koenka, "The relation between self-regulated learning and academic achievement across childhood and adolescence: a meta-analysis," Educational Psychology Review, vol. 28, no. 3, pp 425-474, 2016.

[38] K. Y. Ku and I. T. Ho, "Metacognitive strategies that enhance critical thinking," Metacognition and learning, vol. 5, no. 3, pp. 251-267, 2010.
Copyright $\odot 2019$ by the authors. This is an open access article distributed under the Creative Commons Attribution License which permits unrestricted use, distribution, and reproduction in any medium, provided the original work is properly cited ( $\underline{\text { CC BY 4.0). }}$.

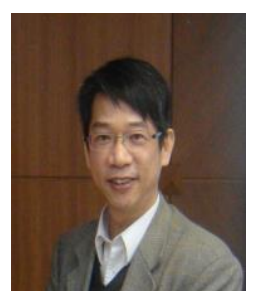

Feng Hsu Wang received the BS degree in information science at National Chiao Tung University, Taiwan, in 1986. He received the MS and $\mathrm{PhD}$ degrees in computer science and information engineering at National Taiwan University in 1988 and 1993 , respectively. He is currently on the faculty in the Department of Computer Science and Information Engineering at Ming Chuan University, where he is now a full professor. His research area is educational data mining, intelligent tutoring systems, with special interests in deep learning and social media mining. 